\title{
Homocysteine alters vasoreactivity of human internal mammary artery by affecting the $\mathrm{K}_{\mathrm{Ca}}$ channel family
}

\author{
Wen-Tao Sun ${ }^{1,2}$, Hong-Mei Xue ${ }^{1,2,3}$, Hai-Tao Hou ${ }^{1}$, Huan-Xin Chen ${ }^{1}$, Jun Wang ${ }^{1}$, Guo-Wei He ${ }^{1,4,5}$, Qin Yang ${ }^{1}$ \\ ${ }^{1}$ Center for Basic Medical Research \& Department of Cardiovascular Surgery, TEDA International Cardiovascular Hospital, Chinese Academy \\ of Medical Sciences \& Peking Union Medical College, Tianjin, China; ${ }^{2}$ School of Medicine, Nankai University, Tianjin, China; ${ }^{3}$ Department of \\ Physiology, Hebei Medical University, Shijiazhuang, China; ${ }^{4}$ School of Pharmacy, Wannan Medical College, Wuhu, China; ${ }^{5}$ Department of Surgery, \\ Oregon Health and Science University, Portland, Oregon, USA \\ Contributions: (I) Conception and design: Q Yang; (II) Administrative support: J Wang; (III) Provision of study materials or patients: GW He; \\ (IV) Collection and assembly of data: WT Sun, HM Xue, HT Hou, HX Chen; (V) Data analysis and interpretation: WT Sun, Q Yang; \\ (VI) Manuscript writing: All authors; (VII) Final approval of manuscript: All authors. \\ Correspondence to: Professor Qin Yang, MD, PhD. TEDA International Cardiovascular Hospital, Chinese Academy of Medical Sciences \& Peking \\ Union Medical College, No.61, $3^{\text {rd }}$ Ave, TEDA, Tianjin 300457, China. Email: qyanghk@163.com.
}

Background: Hyperhomocysteinemia is an independent risk factor for atherosclerotic heart disease. We previously demonstrated that disruption of calcium-activated potassium $\left(\mathrm{K}_{\mathrm{Ca}}\right)$ channel activity is involved in homocysteine-induced dilatory dysfunction of porcine coronary arteries. Recently we reported that the $\mathrm{K}_{\mathrm{Ca}}$ channel family, including large-, intermediate-, and small-conductance $\mathrm{K}_{\mathrm{Ca}}\left(\mathrm{BK}_{\mathrm{Ca}}, \mathrm{IK}_{\mathrm{Ca}}\right.$, and $\left.\mathrm{SK}_{\mathrm{Ca}}\right)$ subtypes, are abundantly expressed in human internal mammary artery (IMA). In this study, we further investigated whether homocysteine affects the expression and functionality of the $\mathrm{K}_{\mathrm{Ca}}$ channel family in this commonly used graft for coronary artery bypass surgery (CABG).

Methods: Residual IMA segments obtained from patients undergoing CABG were studied in a myograph for the role of $\mathrm{K}_{\mathrm{Ca}}$ subtypes in both vasorelaxation and vasoconstriction. The expression and distribution of $\mathrm{K}_{\mathrm{Ca}}$ subtypes were detected by Western blot and immunohistochemistry.

Results: Both the $\mathrm{BK}_{\mathrm{Ca}}$ channel activator NS1619 and the $\mathrm{IK}_{\mathrm{Ca}} / \mathrm{SK}_{\mathrm{Ca}}$ channel activator NS309 evoked significant IMA relaxation. Homocysteine exposure suppressed NS1619-induced relaxation whereas showed no influence on NS309-induced response. Blockade of $\mathrm{BK}_{\mathrm{Ca}}$ but not $\mathrm{IK}_{\mathrm{Ca}}$ and $\mathrm{SK}_{\mathrm{Ca}}$ subtypes significantly suppressed acetylcholine-induced relaxation and enhanced U46619-induced contraction. Homocysteine compromised the vasodilating activity of the $\mathrm{BK}_{\mathrm{Ca}}$ subtype in IMA, associated with a lowered protein level of the $\mathrm{BK}_{\mathrm{Ca}} \beta 1$-subunit. Homocysteine potentiated the role of $\mathrm{IK}_{\mathrm{Ca}}$ and $\mathrm{SK}_{\mathrm{Ca}}$ subtypes in mediating endothelium-dependent relaxation without affecting the expression of these channels.

Conclusions: Homocysteine reduces the expression of $\mathrm{BK}_{\mathrm{Ca}} \beta 1$-subunit and compromises the vasodilating activity of $\mathrm{BK}_{\mathrm{Ca}}$ channels in IMA. Unlike $\mathrm{BK}_{\mathrm{Ca}}, \mathrm{IK}_{\mathrm{Ca}}$ and $\mathrm{SK}_{\mathrm{Ca}}$ subtypes are unessential for IMA vasoregulation, whereas the loss of $\mathrm{BK}_{\mathrm{Ca}}$ functionality in hyperhomocysteinemia enhances the role of $\mathrm{IK}_{\mathrm{Ca}}$ and $\mathrm{SK}_{\mathrm{Ca}}$ subtypes in mediating endothelial dilator function. Targeting $\mathrm{BK}_{\mathrm{Ca}}$ channels may form a strategy to improve the postoperative graft performance in CABG patients with hyperhomocysteinemia who receive IMA grafting.

Keywords: Calcium-activated potassium channels ( $\mathrm{K}_{\mathrm{Ca}}$ channels); coronary artery bypass surgery (CABG); homocysteine; internal mammary artery (IMA)

Submitted Oct 12, 2020. Accepted for publication Jan 17, 2021.

doi: 10.21037/atm-20-6821

View this article at: http://dx.doi.org/10.21037/atm-20-6821

(c) Annals of Translational Medicine. All rights reserved. 


\section{Introduction}

Hyperhomocysteinemia resulting from disorders of homocysteine metabolism is an independent risk factor for atherosclerotic vascular disease and myocardial infarction (1). High concentration of homocysteine impairs vascular endothelial function by reducing nitric oxide (NO) bioavailability (2), in which downregulation of endothelial NO synthase (eNOS) expression and overproduction of reactive oxygen species play a significant role $(3,4)$. Previous studies in hyperhomocysteinemic animal models also reported the unfavorable effect of homocysteine on endothelium-derived hyperpolarizing factor (EDHF) $(5,6)$. EDHF-mediated vasodilatation was compromised in the renal artery of hyperhomocysteinemic rats (6) and mesenteric arteries of hyperhomocysteinemic mice (5). With electrophysiological measurements, we further demonstrated that homocysteine-induced loss of EDHFresponse in porcine coronary arteries is attributed to the inactivation of intermediate- and small-conductance calcium-activated potassium $\left(\mathrm{IK}_{\mathrm{Ca}}\right.$ and $\left.\mathrm{SK}_{\mathrm{Ca}}\right)$ channels in the coronary endothelium (7). Whether homocysteine affects $\mathrm{IK}_{\mathrm{Ca}}$ and $\mathrm{SK}_{\mathrm{Ca}}$ channels in human vessels remains barely studied.

In addition to $\mathrm{IK}_{\mathrm{Ca}}$ and $\mathrm{SK}_{\mathrm{Ca}}$, there is another $\mathrm{K}_{\mathrm{Ca}}$ channel subtype called large-conductance $\mathrm{K}_{\mathrm{Ca}}\left(\mathrm{BK}_{\mathrm{Ca}}\right)$, which is formed by a tetramer of the pore-forming $\alpha$-subunit and the regulatory $\beta$-subunit ( $\beta 1$ isoform in vasculature) (8). $\mathrm{BK}_{\mathrm{Ca}}$ channels are abundantly expressed in smooth muscle cells and play an important role in the regulation of vascular tone. Activation of $\mathrm{BK}_{\mathrm{Ca}}$ channels causes membrane hyperpolarization. The consequent closure of voltagedependent $\mathrm{Ca}^{2+}$ channels leads to reduced $\mathrm{Ca}^{2+}$ entry and subsequent relaxation of smooth muscle cells (9). $\mathrm{BK}_{\mathrm{Ca}}$ channels are a target site of NO and EDHF (10-12). Electrophysiological experiments showed the inhibitory effect of homocysteine on $\mathrm{BK}_{\mathrm{Ca}}$ channel activity in both animal and human vascular smooth muscle cells $(13,14)$. Recent mechanistic studies from our group demonstrated that endoplasmic reticulum stress-mediated downregulation of $\mathrm{BK}_{\mathrm{Ca}} \beta 1$ is involved in homocysteine-induced $\mathrm{BK}_{\mathrm{Ca}}$ channel inhibition in porcine coronary arteries $(15,16)$. There is a lack of studies regarding the effect of homocysteine on the functionality of $\mathrm{BK}_{\mathrm{Ca}}$ channels in human vessels.

Internal mammary artery (IMA) is one of the most commonly used grafts for coronary artery bypass surgery (CABG). We previously reported the reduction of $\mathrm{NO}$ bioavailability and the impairment of endothelial dilator function of IMA caused by elevated level of homocysteine (17). Recently, we clarified the expression and distribution profile and the functionality of the $\mathrm{K}_{\mathrm{Ca}}$ channel family in IMA. IMA expresses all three $\mathrm{K}_{\mathrm{Ca}}$ subtypes and each subtype distributes in both endothelium and smooth muscle (18). In comparison with the $\mathrm{BK}_{\mathrm{Ca}}$ subtype that significantly contributes to the dilatation of IMA, both $\mathrm{IK}_{\mathrm{Ca}}$ and $\mathrm{SK}_{\mathrm{Ca}}$ subtypes play a minor role in IMA dilatation under physiological conditions. Whether the function of $\mathrm{K}_{\mathrm{Ca}}$ channel family alters in pathological states such as hyperhomocysteinemia needs to be further explored.

The present study investigated the effect of homocysteine on $\mathrm{K}_{\mathrm{Ca}}$ channels in IMA. The role played by each $\mathrm{K}_{\mathrm{Ca}}$ subtype in vasodilatation and vasoconstriction was studied, along with the determination of channel expression. This study for the first time revealed the impact of hyperhomocysteinemia on the $\mathrm{K}_{\mathrm{Ca}}$ channel family in human vasculature.

We present the following article in accordance with the MDAR reporting checklist (available at http://dx.doi. org/10.21037/atm-20-6821).

\section{Methods}

Residual IMA segments $(n=76)$ that would otherwise be discarded were collected with the consent of the patients undergoing CABG. The study was conducted in accordance with the Declaration of Helsinki (as revised in 2013). The study protocol was approved by the Institutional Ethics Review Board of TEDA International Cardiovascular Hospital ([2018]-0626-2).

The residual IMA segment from each patient was divided into two ring segments ( $3 \mathrm{~mm}$ length) and randomly allocated to control group and homocysteine-treated group respectively. The homocysteine-treated segment was incubated with $100 \mu \mathrm{mol} / \mathrm{L}$ homocysteine (Sigma Aldrich, Cat\#H4628) in fresh oxygenated Krebs solution at $37{ }^{\circ} \mathrm{C}$ in a $5 \% \mathrm{CO}_{2}$ incubator for $24 \mathrm{~h}$ and the control was incubated under the same condition in Krebs containing equal volume of vehicle (distilled $\mathrm{H}_{2} \mathrm{O}$ ). After $24 \mathrm{~h}$, the vessels were collected for (I) vasoreactivity studies for the functional role of $\mathrm{K}_{\mathrm{Ca}}$ channels, and (II) Western blot and immunohistochemistry staining for the expression of $\mathrm{K}_{\mathrm{Ca}}$ channels.

\section{Vasoreactivity study}

The IMA segments were mounted in isolated chambers of a multi wire myograph system (Model 620M, J.P.Trading, Aarhus, Denmark). The ring segments were permitted 
to equilibrate for $30-60 \mathrm{~min}$ at $37^{\circ} \mathrm{C}$ then normalized by setting them to an internal circumference equivalent to a $90 \%$ of the circumference at a passive transmural pressure of $100 \mathrm{mmHg}$, as in our previous studies (15-18).

\section{Vasoconstriction}

Following a 40 -min equilibration period, cumulative increasing concentrations of the thromboxane $\mathrm{A}_{2}\left(\mathrm{TXA}_{2}\right)$ mimetic U46619 (-11--4.5 LogM) (Cayman Chemical, Cat\#16450) were added in the myograph chamber to generate a concentration-response curve. The role played by each $\mathrm{K}_{\mathrm{Ca}}$ channel subtype in the regulation of IMA constriction was further characterized by comparing a first concentration-response curve constructed in control conditions with a second concentration-response curve constructed in the same ring segment after a selective inhibition of the subtype. The $\mathrm{BK}_{\mathrm{Ca}}$ subtype blocker iberiotoxin (100 nmol/L) (Alomone labs, Cat\#STI-400) (group Ia), the $\mathrm{IK}_{\mathrm{Ca}}$ subtype blocker TRAM-34 $(1 \mu \mathrm{mol} / \mathrm{L}$ ) (Alomone labs, Cat\#T-105) (group Ib), or the $\mathrm{SK}_{\mathrm{Ca}}$ subtype blocker apamin (100 nmol/L) (Alomone labs, Cat\#STA-200) (group Ic) were added individually or in combination (group Id: TRAM-34 + apamin, group Ie: iberiotoxin + TRAM34 + apamin) 30 min prior to contraction with U46619. For vessels pretreated with TRAM-34 + apamin, or iberiotoxin + TRAM- 34 + apamin, the drugs were added in a randomized order.

\section{Vasorelaxation}

To assess the role of $\mathrm{K}_{\mathrm{Ca}}$ channel subtypes in relaxation, the IMA ring segments were preconstricted with U46619. Cumulative dose-response curves were then established for (I) $\mathrm{BK}_{\mathrm{Ca}}$ channel activator NS1619 (-9-4.5 LogM) (MedChemExpress, Cat\#HY-12496), or (II) $\mathrm{IK}_{\mathrm{Ca}} / \mathrm{SK}_{\mathrm{Ca}}$ channel activator NS309 (-9--4.5 LogM) (MedChemExpress, Cat\#HY-15416), or (III) acetylcholine (-10--4.5 LogM) (Sigma Aldrich, Cat\#A6625) when the contraction reached a plateau.

For studies using acetylcholine, five sets of experiments (group IIa-IIe) were performed. In each set, two consecutive concentration-response curves for acetylcholine were constructed in the same ring segment: a first one in control conditions and a second one after pharmacological blockade of different $\mathrm{K}_{\mathrm{Ca}}$ subtypes. Iberiotoxin $(100 \mathrm{nmol} / \mathrm{L})$ (group IIa), TRAM-34 (1 $\mathrm{mol} / \mathrm{L}$ ) (group IIb), or apamin $(100 \mathrm{nmol} / \mathrm{L})$ (group IIc) were used alone or in combination to pretreat the vessels for $30 \mathrm{~min}$ before U46619preconstriction. For vessels pretreated with TRAM-34 + apamin (group IId) or iberiotoxin + TRAM-34 + apamin (group IIe), the drugs were added in a randomized order.

To ensure the comparability of the relaxant response in the two consecutive relaxation studies and between control and homocysteine-treated groups, similar extent of precontraction was achieved by using varied concentration of U46619 ranging from -8.5 to $-7 \operatorname{LogM}$.

\section{Western blot analysis}

The IMA segment from each patient was divided into two groups and treated without (control) or with homocysteine $(100 \mu \mathrm{mol} / \mathrm{L})$ for $24 \mathrm{~h}$. Details of the western blot procedures were published elsewhere $(7,15,16,18)$. In brief, whole cell protein was extracted using RIPA buffer (Solarbio, China) supplemented with protease and phosphatase inhibitors (Thermo Fisher Scientific, USA). After determination of protein concentration, the samples were aliquoted and fractionated by sodium dodecyl sulfate polyacrylamide gel electrophoresis ( $30 \mu \mathrm{g} / \mathrm{lane})$ for $90 \mathrm{~min}$ at $100 \mathrm{~V}$, followed by electro-transferred to polyvinylidene difluoride (PVDF) membrane (Thermo Fisher Scientific, USA) for $90 \mathrm{~min}$ at $100 \mathrm{~V}$. The PVDF membrane was then blocked with $3 \%$ BSA/TBS for $1 \mathrm{~h}$ at room temperature and probed overnight at $4{ }^{\circ} \mathrm{C}$ in $1 \times$ TBS containing $3 \%$ BSA with primary antibodies (Abcam, USA) against the protein of interest, including $\mathrm{BK}_{\mathrm{Ca}} \alpha(1: 1,000$, Abcam, ab3586, AB_2131256), $\mathrm{BK}_{\mathrm{Ca}} \beta 1$ (1:200, Abcam, ab3587, AB_303932), $\mathrm{K}_{\mathrm{Ca}} 3.1\left(\mathrm{IK}_{\mathrm{Ca}}\right)(1: 500$, Abcam, ab75956, AB_1952001), and $\mathrm{K}_{\mathrm{Ca}} 2.3\left(\mathrm{SK}_{\mathrm{Ca}}\right)$ (1:500, GeneTex, GTX47693, AB_11173990). The membrane was washed and incubated with horseradish peroxidase (HRP)-conjugated goat anti-rabbit IgG or horse anti-mouse $\operatorname{IgG}$ secondary antibodies $(1: 3,000$, Cell signaling technology, USA, 7074, AB_2099233; 7076, $\left.\mathrm{AB} \_330924\right)$ for $1 \mathrm{~h}$ at room temperature under gentle agitation. $\beta$-actin (1:2,000, Absin, China, abs137975) was used as internal loading control. Color development was performed with electrochemiluminescence kit (Beyotime, China), followed by imaging using G:BOX gel doc system (Syngene, UK). The intensity of the bands was analyzed by Quantity One imaging system (Version 4.6.6, Bio-Rad).

\section{Histology and immunobistochemistry staining}

The IMA segment from each patient was divided into control and homocysteine-treated $(100 \mu \mathrm{mol} / \mathrm{L})$ groups. 
After incubation for $24 \mathrm{~h}$, the vessels were fixed in $4 \%$ paraformaldehyde, decalcified, dehydrated, and embedded in paraffin. The embedded tissue samples were sliced into 4-5 $\mu \mathrm{m}$ sections and stained with haematoxylin and eosin after deparaffination. For immunohistochemistry staining, slides were heated at $100{ }^{\circ} \mathrm{C}$ in $10 \mathrm{mmol} / \mathrm{L}$ tannic acid/1 mmol/L EDTA solution (ZSGB-BIO, China) to retrieve antigens and treated with $3 \% \mathrm{H}_{2} \mathrm{O}_{2}$ (ZSGB-BIO, China) to inactive endogenous peroxidase. Sections were incubated for $60 \mathrm{~min}$ at $37^{\circ} \mathrm{C}$ with primary antibodies against $\mathrm{BK}_{\mathrm{Ca}} \alpha(1: 4,000), \mathrm{BK}_{\mathrm{Ca}} \beta 1(1: 500), \mathrm{K}_{\mathrm{Ca}} 3.1$ (1:800), or $\mathrm{K}_{\mathrm{Ca}} 2.3$ (1:800), followed by 30-min incubation with goat anti-rabbit IgG HRP-conjugated secondary antibody at room temperature for signal detection of $\mathrm{K}_{\mathrm{Ca}}$ subtypes. Afterwards, the specimens were washed in PBS and stained with 3,3'-diaminobenzidine (DAB, ZSGB-BIO, China). Counterstaining was performed with Mayer's haematoxylin (ZSGB-BIO, China). Negative controls were immunostained without the primary antibody. The immunostained images were captured using a microscope (Olympus BX43, Japan).

Immunostaining was evaluated by two independent pathologists using a blind protocol design. For each specimen, the histoscore (H-score) of each $\mathrm{K}_{\mathrm{Ca}}$ channel subtype was calculated as the sum of staining intensity as previously described (18) (0-3, negative staining: 0 ; weak staining: 1 ; moderate staining: 2 ; and strong staining: 3 ) multiplied by the percentage of stained cells $(0-100 \%)$.

\section{Statistical analysis}

Protein expression of targets of interest was normalized to the expression of $\beta$-actin. Relaxation was expressed as the percentage decrease in isometric force induced by U46619. The effective concentration of vasodilator/ vasoconstrictor that caused $50 \%$ of maximal relaxation/ constriction was defined as $\mathrm{EC}_{50}$. The $\mathrm{EC}_{50}$ was determined from each concentration-relaxation/constriction curve by a logistic, curve-fitting equation: $\mathrm{E}=\mathrm{MA}^{\mathrm{P}} /\left(\mathrm{A}^{\mathrm{P}}+\mathrm{K}^{\mathrm{P}}\right)$, where $\mathrm{E}$ is response, $\mathrm{M}$ is maximal relaxation/constriction, $\mathrm{A}$ is concentration, $\mathrm{K}$ is $\mathrm{EC}_{50}$ concentration, and $\mathrm{P}$ is the slope parameter. A two-sided significance level of 0.05 and a power of $80 \%$ were used to determine the sample size to show a $20 \%$ difference for comparison, based on the variance seen in our previous studies of vasoreactivity of the human IMA.

Data were expressed as mean \pm SEM. Student's t-test, one-way ANOVA (Scheffe F test), and two-way repeated measures ANOVA (SPSS, version 20) were used for statistical analysis when appropriate. $\mathrm{P}<0.05$ was considered statistically significant.

\section{Results}

\section{Effect of homocysteine on the role of $K_{C a}$ subtypes in the regulation of IMA contractility}

Blockade of the $\mathrm{BK}_{\mathrm{Ca}}$ subtype with iberiotoxin significantly enhanced U46619-induced vasoconstriction $(\mathrm{P}=0.047$, twoway repeated measures ANOVA) (Rmax: $71.3 \pm 12.7$ vs. $50.1 \pm 4.9 \mathrm{mN}$ in control, $\mathrm{P}=0.152$; contraction at $-7.5 \log \mathrm{M}$ : $66.3 \pm 11.9$ vs. $37.6 \pm 5.9 \mathrm{mN}$ in control, $\mathrm{P}=0.048)$. The sensitivity to $\mathrm{U} 46619$ tended to increase $\left(\mathrm{EC}_{50}\right.$ : $-9.01 \pm 0.27$ vs. $-8.34 \pm 0.25 \mathrm{LogM}$ in control, $\mathrm{P}=0.096$ ) (Figure $1 \mathrm{~A} \&$ Table 1). In comparison, inhibition of the $\mathrm{IK}_{\mathrm{Ca}}$ or the $\mathrm{SK}_{\mathrm{Ca}}$ subtype by TRAM-34 or apamin respectively or jointly barely affected the contractile response and sensitivity of IMA to U46619 (Figure 1B,C,D \& Table 1). Interestingly, although iberiotoxin caused a marked enhancement of U46619-induced vasoconstriction, co-treatment with iberiotoxin, TRAM-34, and apamin did not significantly increase the maximal contractile response though the contraction seemed to be enhanced at low doses of U46619 (Figure 1E).

Homocysteine exposure augmented the contractile response of IMA to U46619 ( $\mathrm{P}=0.033$, two-way repeated measures ANOVA) (Rmax: $71.3 \pm 7.0$ vs. $50.1 \pm 4.9 \mathrm{mN}$ in control, $\mathrm{P}=0.032$ ) (Figure 1A). The enhancement effect of iberiotoxin on the vasoconstriction was blunted after homocysteine exposure $(\mathrm{P}=0.596$, homocysteine $v s$. homocysteine + iberiotoxin, two-way repeated measures ANOVA, Rmax: $66.4 \pm 16.3$ vs. $71.3 \pm 7.0 \mathrm{mN}, \mathrm{P}=0.786$ ) (Figure 1A \& Table 1). Application of TRAM-34 and apamin, either individually (Figure 1B,C) or jointly (Figure 1D), showed no effect on U46619-induced constriction in homocysteine-exposed IMA. Further triple blockade of $\mathrm{BK}_{\mathrm{Ca}}, \mathrm{IK}_{\mathrm{Ca}}$, and $\mathrm{SK}_{\mathrm{Ca}}$ subtypes also insignificantly affected the contractile response (Figure $1 E$ ). In addition, in homocysteine-exposed IMA, the $\mathrm{EC}_{50}$ values for U46619 remained unshifted after pretreatment with $\mathrm{K}_{\mathrm{Ca}}$ blockers (Table 1).

\section{Effect of homocysteine on the relaxant response of IMA to $K_{C a}$ channel activators}

Both the $\mathrm{BK}_{\mathrm{Ca}}$ channel activator NS1619 and the $\mathrm{IK}_{\mathrm{Ca}}$ / $\mathrm{SK}_{\mathrm{Ca}}$ channel activator NS309 elicited dose-dependent 

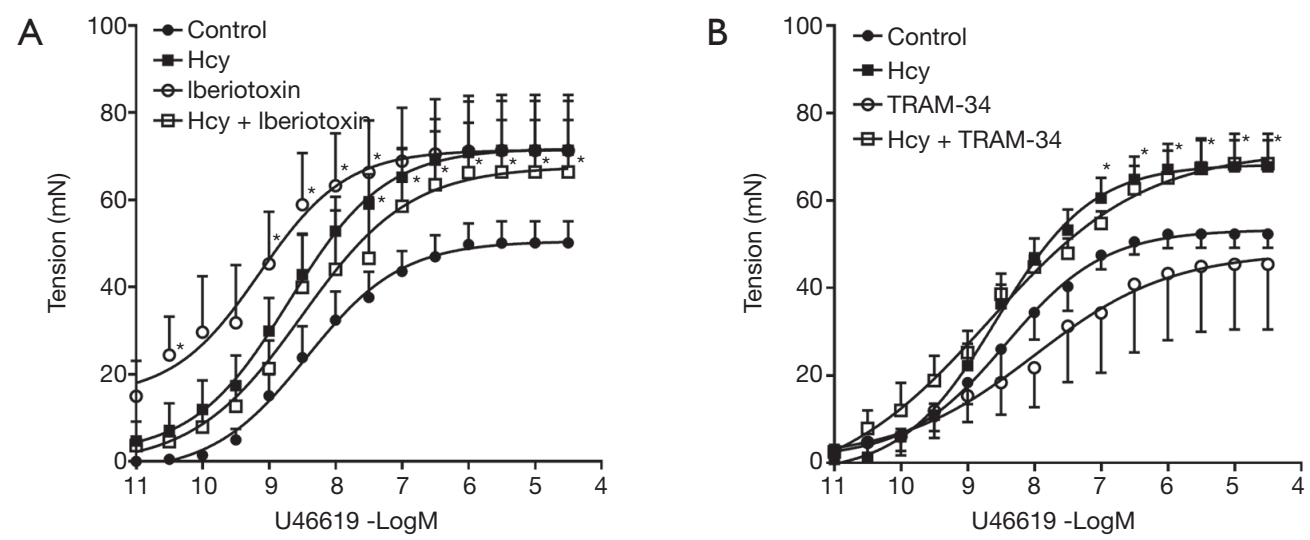

C
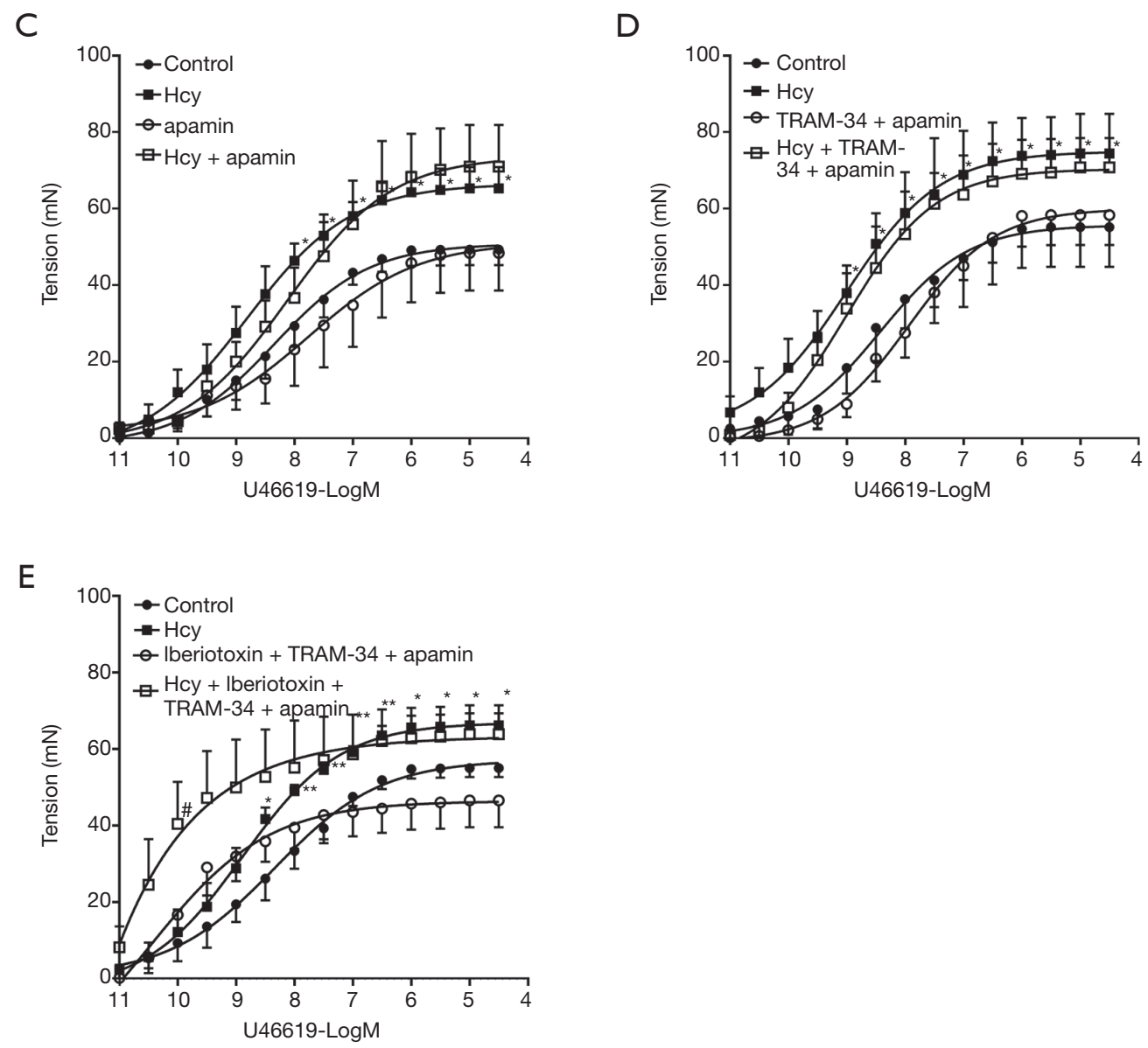

Figure 1 Effect of homocysteine (Hcy) on the role of $\mathrm{K}_{\mathrm{Ca}}$ subtypes in the regulation of internal mammary artery (IMA) contractility. Hcy enhances the contractile response of IMA to U46619 and compromises the activity of the $\mathrm{BK}_{\mathrm{Ca}}$ channel subtype in opposing vasoconstriction (A). Neither $\mathrm{IK}_{\mathrm{Ca}}$ nor $\mathrm{SK}_{\mathrm{Ca}}$ channel subtype is involved in U46619-induced contraction in IMAs exposed or not exposed to homocysteine (B,C,D). The $\mathrm{K}_{\mathrm{Ca}}$ channel family is barely involved in the regulation of IMA contractility in hyperhomocysteinemic condition $(\mathrm{E})$. $\mathrm{n}=6 .{ }^{*} \mathrm{P}<0.05$, ${ }^{* *} \mathrm{P}<0.01$ vs. control; ${ }^{\#} \mathrm{P}<0.05$ vs. Hcy. Iberiotoxin: $\mathrm{BK}_{\mathrm{Ca}}$ channel blocker; TRAM-34: $\mathrm{IK}_{\mathrm{Ca}}$ channel blocker; apamin: $\mathrm{SK}_{\mathrm{Ca}}$ channel blocker. 
Table 1 Effect of $\mathrm{K}_{\mathrm{Ca}}$ channel blockers on $\mathrm{EC}_{50}$ values for $\mathrm{U} 46619$ in internal mammary artery (IMA) subjected or not subjected to homocysteine exposure ( $\mathrm{n}=6$ in each group)

\begin{tabular}{|c|c|c|c|c|c|}
\hline Group & \multicolumn{2}{|c|}{ Without homocysteine exposure } & \multicolumn{2}{|c|}{ With homocysteine exposure } & $P$ value \\
\hline \multicolumn{6}{|l|}{ la } \\
\hline Control & $-8.34 \pm 0.25$ & & $-9.05 \pm 0.42$ & & 0.176 \\
\hline Iberiotoxin & $-9.01 \pm 0.27$ & 0.096 & $-8.90 \pm 0.41$ & 0.804 & 0.830 \\
\hline Control & $-8.43 \pm 0.28$ & & $-8.59 \pm 0.15$ & & 0.614 \\
\hline TRAM-34 & $-7.71 \pm 0.43$ & 0.186 & $-8.61 \pm 0.48$ & 0.966 & 0.189 \\
\hline \multicolumn{6}{|l|}{ Ic } \\
\hline Control & $-8.51 \pm 0.45$ & & $-8.71 \pm 0.17$ & & 0.681 \\
\hline Control & $-8.39 \pm 0.25$ & & $-9.03 \pm 0.42$ & & 0.223 \\
\hline TRAM-34 + apamin & $-7.95 \pm 0.24$ & 0.234 & $-8.48 \pm 0.44$ & 0.390 & 0.338 \\
\hline \multicolumn{6}{|l|}{ le } \\
\hline Control & $-8.58 \pm 0.44$ & & $-8.77 \pm 0.08$ & & 0.684 \\
\hline Iberiotoxin + TRAM-34 + apamin & $-9.49 \pm 0.28$ & 0.114 & $-9.92 \pm 0.68$ & 0.125 & 0.571 \\
\hline
\end{tabular}

$\mathrm{K}_{\mathrm{Ca}}$ channel, calcium-activated potassium channel; $\mathrm{EC}_{50}$, concentration for $50 \%$ of maximal effect.

relaxation in IMA. Homocysteine exposure significantly suppressed NS1619-induced relaxation (Rmax: $31.8 \% \pm 1.7 \%$ vs. $51.0 \% \pm 3.1 \%$ in control, $\mathrm{P}<0.001$ ) (Figure $2 A$ ) whereas showed no influence on NS309-induced relaxation (Rmax: $81.5 \% \pm 5.2 \%$ vs. $79.0 \% \pm 6.7 \%$ in control, $\mathrm{P}=0.760$ ) (Figure $2 B$ ).

\section{Effect of homocysteine on the role of $K_{C a}$ subtypes in endothelium-dependent relaxation in IMA}

Blockade of $\mathrm{BK}_{\mathrm{Ca}}$ channels with iberiotoxin significantly inhibited acetylcholine-induced relaxation $(\mathrm{P}<0.0001$, twoway repeated measures ANOVA; Rmax: $41.9 \% \pm 5.5 \%$ vs. $72.6 \% \pm 3.4 \%, \mathrm{P}<0.001$ ) (Figure $3 A$ ). Application of the $\mathrm{IK}_{\mathrm{Ca}}$ channel blocker TRAM-34 and the $\mathrm{SK}_{\mathrm{Ca}}$ channel blocker apamin, individually (Figure 3B,C) or jointly (Figure 3D), barely suppressed the relaxant response of IMA to acetylcholine. Combination of TRAM-34, apamin, and iberiotoxin showed similar inhibition on acetylcholineinduced relaxation $(36.9 \% \pm 6.1 \%$ vs. $79.9 \% \pm 4.7 \%, \mathrm{P}<0.001)$ as compared to iberiotoxin alone, which further suggests the dominant contribution of the $\mathrm{BK}_{\mathrm{Ca}}$ subtype to IMA dilatation (Figure 3E).

Homocysteine exposure suppressed the relaxant response of IMA to acetylcholine $(\mathrm{P}=0.028$, two-way repeated measures ANOVA) with the maximal relaxation decreasing from $72.6 \% \pm 3.4 \%$ to $56.5 \% \pm 5.3 \%(\mathrm{P}=0.029)$ (Figure $3 A)$. The $\mathrm{EC}_{50}$ remained unchanged after homocysteine exposure (Table 2). Iberiotoxin showed no inhibition on acetylcholine-induced relaxation in homocysteine-exposed IMA $(56.2 \% \pm 7.7 \%)$ (Figure $3 A$ ). The diminished inhibitory effect of iberiotoxin suggested that the role of $\mathrm{BK}_{\mathrm{Ca}}$ subtype in IMA dilatation was compromised by homocysteine. In contrast, after homocysteine exposure, acetylcholineinduced relaxation was significantly inhibited by TRAM34 ( $\mathrm{P}<0.0001$, two-way repeated measures ANOVA; Rmax: $38.3 \% \pm 10.6 \%$ vs. $65.9 \% \pm 4.9 \%, \mathrm{P}=0.056$; relaxation at $-5.5 \mathrm{Log} M: 34.6 \% \pm 10.6 \%$ vs. $63.3 \% \pm 4.3 \%, \mathrm{P}=0.046)$ (Figure $3 B)$ and apamin $(\mathrm{P}=0.018$, two-way repeated measures ANOVA; Rmax: $28.9 \% \pm 8.1 \%$ vs. $58.2 \pm 3.7 \%$, $\mathrm{P}=0.013$ ) (Figure 3C). Combined application of TRAM34 and apamin (Rmax: $36.3 \% \pm 5.5 \%$ vs. $54.4 \% \pm 7.0 \%$ ), even in conjunction with iberiotoxin (Rmax: $42.5 \% \pm 7.6 \%$ 

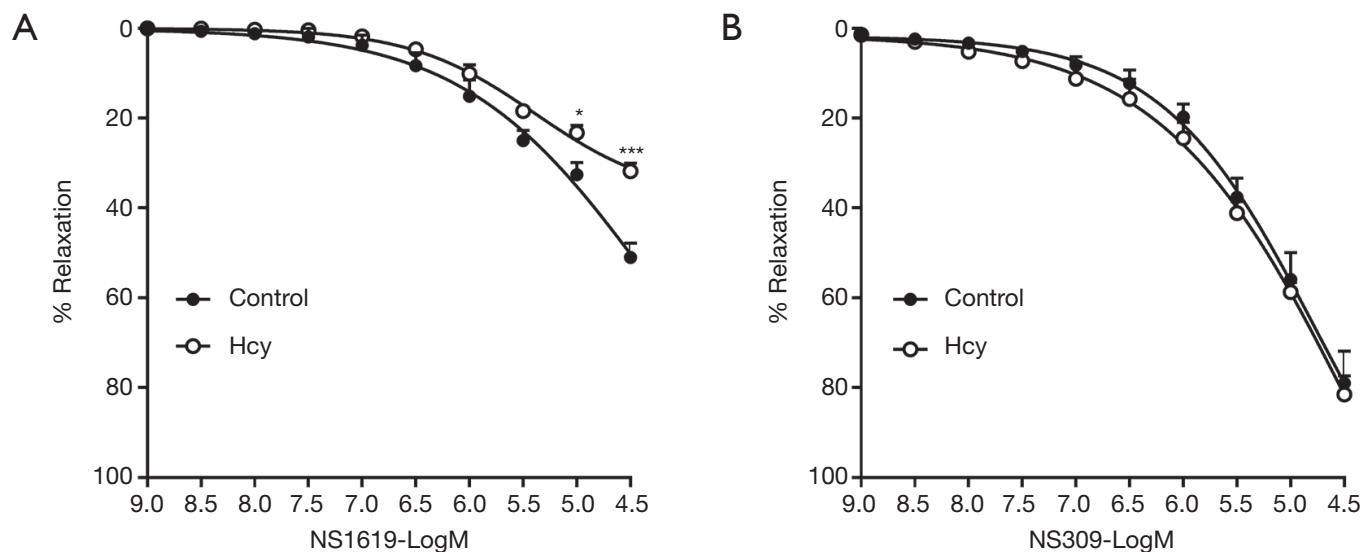

Figure 2 Effect of homocysteine (Hcy) on the relaxant response of internal mammary artery (IMA) to $\mathrm{K}_{\mathrm{Ca}}$ channel activators. Hcy exposure significantly suppressed the $\mathrm{BK}_{\mathrm{Ca}}$ channel activator NS1619-induced relaxation (A) whereas showed no influence on the IK $\mathrm{CK}_{\mathrm{Ca}} / \mathrm{SK}_{\mathrm{Ca}}$ channel activator NS309-induced response (B). $\mathrm{n}=6$. ${ }^{*} \mathrm{P}<0.05$, ${ }^{* * *} \mathrm{P}<0.001$ vs. control.

vs. $56.1 \% \pm 6.2 \%)$, did not show further inhibition on the relaxation in homocysteine-exposed IMA (Figure 3D,E), as compared to TRAM-34 or apamin alone. The significant inhibitory effect of TRAM-34 and apamin suggested that contribution of $\mathrm{IK}_{\mathrm{Ca}}$ and $\mathrm{SK}_{\mathrm{Ca}}$ subtypes to IMA dilatation increases under hyperhomocysteinemic conditions.

Application of different $\mathrm{K}_{\mathrm{Ca}}$ blockers did not shift the $\mathrm{EC}_{50}$ of acetylcholine. Only in IMA treated with blockers of all three $\mathrm{K}_{\mathrm{Ca}}$ subtypes, the $\mathrm{EC}_{50}$ was right-shifted, which however was reverted by homocysteine exposure (Table 2).

Table 3 showed the resting force and U46619-induced preconstriction in each set of the experiments. No significant differences were observed in the resting force and precontraction between the groups incubated with or without homocysteine or between pre- and post-treatment with $\mathrm{K}_{\mathrm{Ca}}$ blockers ( $\mathrm{P}>0.05$ in all sets of experiments). This ensured the reliability and accuracy of the comparison between control and homocysteine-treated IMAs concerning the role of $\mathrm{K}_{\mathrm{Ca}}$ channels in relaxation.

\section{Effect of homocysteine on the expression of $K_{C a}$ subtypes in IMA}

Western blot results showed that homocysteine exposure significantly lowered the protein level of $\mathrm{BK}_{\mathrm{Ca}} \beta 1$ whereas without influencing the level of $\mathrm{BK}_{\mathrm{Ca}} \alpha$ in IMA. The protein level of $\mathrm{IK}_{\mathrm{Ca}}$ and $\mathrm{SK}_{\mathrm{Ca}}$ subtypes was unaltered by homocysteine exposure (Figure 4A,B). Downregulation of the $\mathrm{BK}_{\mathrm{Ca}} \beta 1$-subunit by homocysteine was further shown by immunohistochemistry staining (Figure 4C,D).
$\mathrm{H}$-score calculated from seven independent experiments suggested that the $\mathrm{BK}_{\mathrm{Ca}} \beta 1$-subunit was significantly less in homocysteine-exposed IMA as compared to the vessels without homocysteine exposure $(\mathrm{P}=0.038)$. The H-score of $\mathrm{IK}_{\mathrm{Ca}}$ or $\mathrm{SK}_{\mathrm{Ca}}$ subtypes did not differ between control and homocysteine-exposed IMAs, which was consistent with the western blot results showing the unaltered protein level of $\mathrm{IK}_{\mathrm{Ca}}$ and $\mathrm{SK}_{\mathrm{Ca}}$ subtypes after homocysteine exposure.

\section{Discussion}

IMA subjected to homocysteine exposure showed significantly suppressed response to acetylcholine. Such suppression could be attributed, at least partially, to the inhibition of $\mathrm{BK}_{\mathrm{Ca}}$ channels, which was suggested by the diminished efficacy of iberiotoxin in inhibiting acetylcholine-induced relaxation in homocysteine-exposed IMA. The blunted relaxant response of IMA to the $\mathrm{BK}_{\mathrm{Ca}}$ channel activator NS1619 after homocysteine exposure also supported the notion that homocysteine inhibits the vasodilatory activity of the $\mathrm{BK}_{\mathrm{Ca}}$ subtype in IMA. Previously we reported that decrease of eNOS-NO bioavailability is involved in homocysteine-induced endothelial dysfunction of IMA (17). Taking into account that $\mathrm{BK}_{\mathrm{Ca}}$ channels are an effector of $\mathrm{NO}(11,19)$, we suggested that compromised $\mathrm{BK}_{\mathrm{Ca}}$ channel activity may also be partially responsible for the impaired NO-mediated relaxation in IMA in hyperhomocysteinemic states.

The significant vasodilatory role of the $\mathrm{BK}_{\mathrm{Ca}}$ subtype in IMA and the inhibition by homocysteine was further 

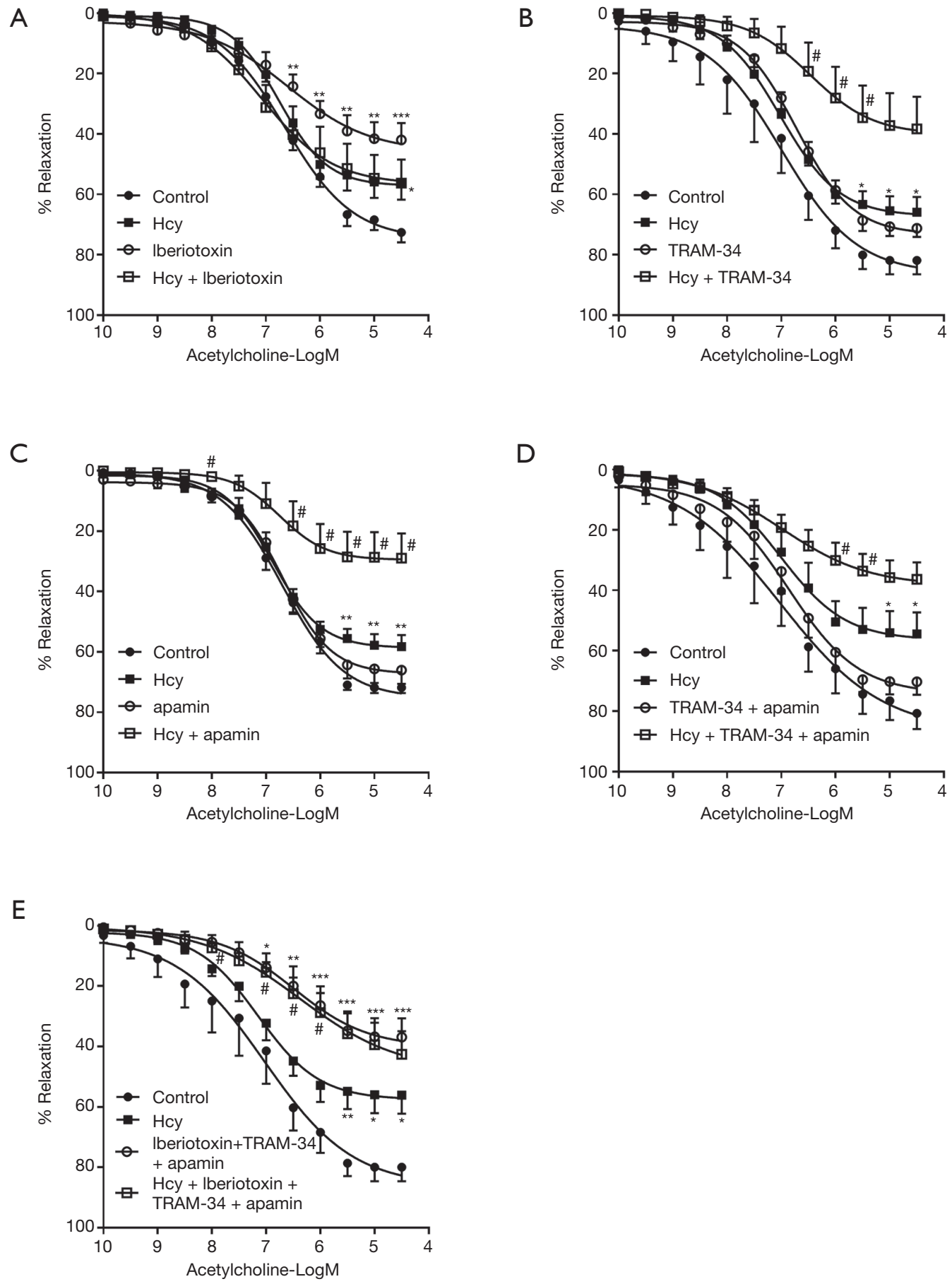

Figure 3 Effect of homocysteine (Hcy) on the role of $\mathrm{K}_{\mathrm{Ca}}$ subtypes in endothelium-dependent relaxation in internal mammary artery (IMA).

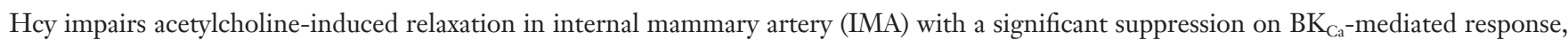
suggested by the diminished inhibitory effect of the $\mathrm{BK}_{\mathrm{Ca}}$ channel blocker iberiotoxin (A). Both $\mathrm{IK}_{\mathrm{Ca}}$ and $\mathrm{SK}_{\mathrm{Ca}}$ subtypes play a minor role in IMA dilatation whereas their contribution increases after homocysteine exposure, shown by the increased efficacy of IK $\mathrm{Ca}_{\mathrm{Ca}}$ and $\mathrm{SK}_{\mathrm{Ca}}$ channel blockers TRAM-34 and apamin in inhibiting acetylcholine-induced relaxation (B,C,D). In homocysteine-exposed IMA, triple blockade of $\mathrm{K}_{\mathrm{Ca}}$ channels shows no further inhibition on the relaxation as compared to double blockade of $\mathrm{IK}_{\mathrm{Ca}}$ and $\mathrm{SK}_{\mathrm{Ca}}$ channels, further suggesting the loss of $\mathrm{BK}_{\mathrm{Ca}}-$ mediation caused by homocysteine (E). $\mathrm{n}=6$. ${ }^{*} \mathrm{P}<0.05,{ }^{* *} \mathrm{P}<0.01,{ }^{* * *} \mathrm{P}<0.001$ vs. control; ${ }^{*} \mathrm{P}<0.05$ vs. Hcy. 
Table 2 Effect of $\mathrm{K}_{\mathrm{Ca}}$ channel blockers on $\mathrm{EC}_{50}$ values for acetylcholine in internal mammary artery (IMA) subjected or not subjected to homocysteine exposure ( $\mathrm{n}=6$ in each group)

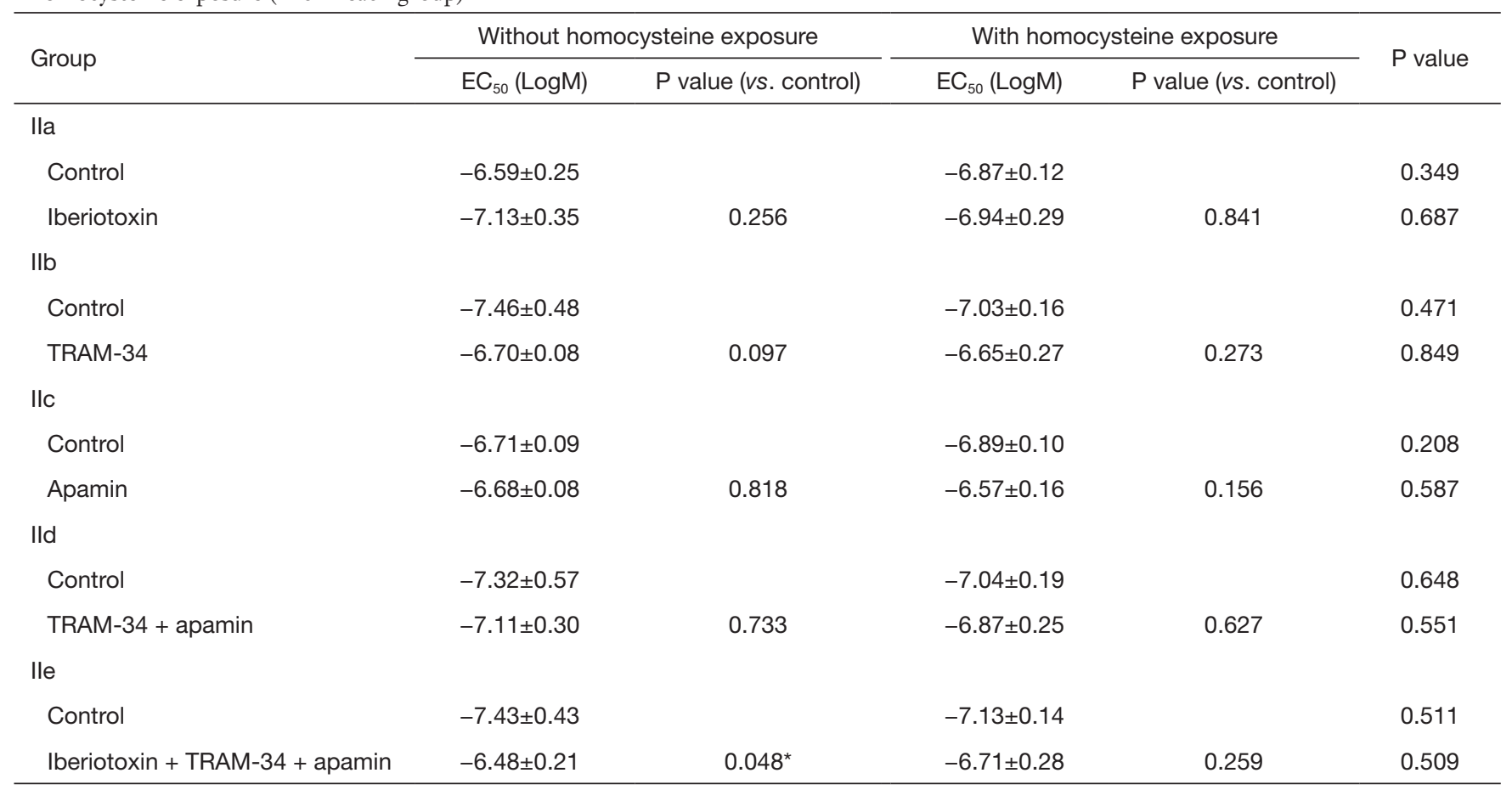

${ }^{*}, \mathrm{P}<0.05 . \mathrm{K}_{\mathrm{Ca}}$ channel, calcium-activated potassium channel; $\mathrm{EC}_{50}$, concentration for $50 \%$ of maximal effect.

Table 3 Resting force and U46619-precontraction of internal mammary artery (IMA) in the study of acetylcholine-induced relaxation (n=6 in each group)

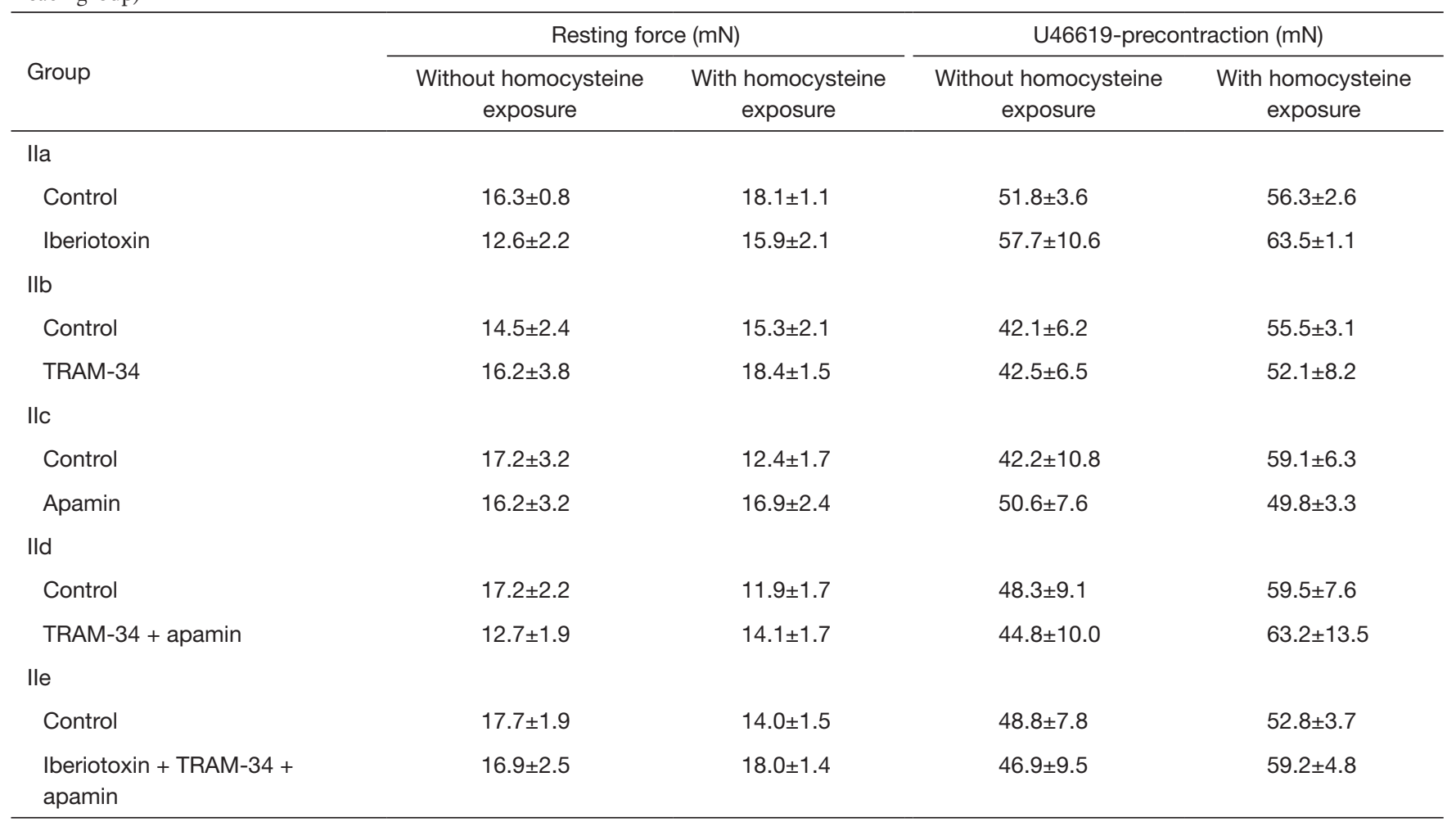


A

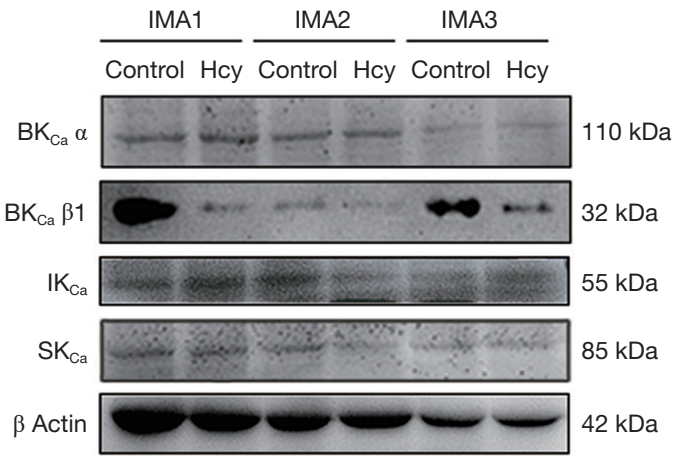

C

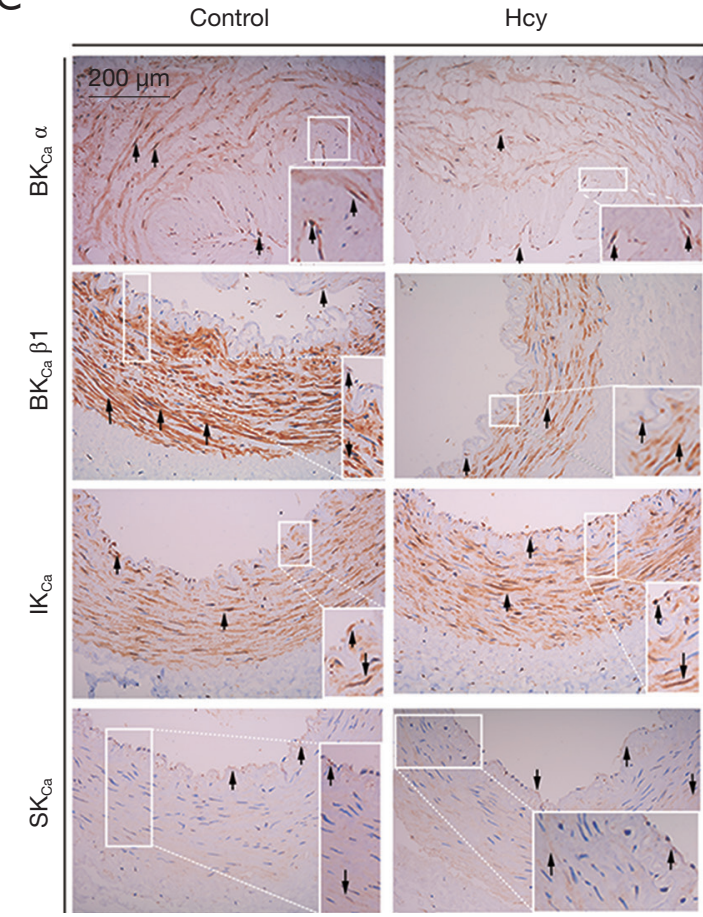

B

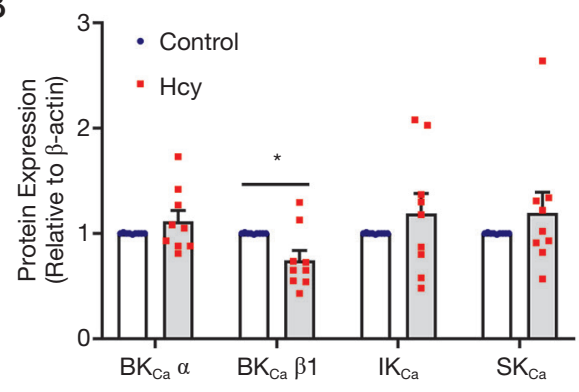

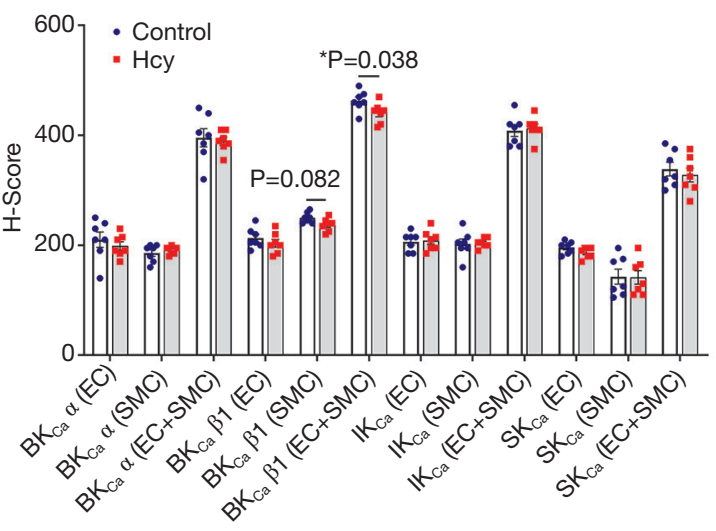

Figure 4 Effect of homocysteine (Hcy) on the expression of $\mathrm{K}_{\mathrm{Ca}}$ channels in internal mammary artery (IMA). Immunoblotting of cell lysate prepared from IMA samples using the indicated antibodies (A). Protein levels of $\mathrm{K}_{\mathrm{Ca}}$ subtypes in homocysteine-exposed IMAs compared with those without homocysteine exposure (B, $n=9$ ). Immunohistochemistry images (magnification 400x) showing the distribution and expression of $\mathrm{K}_{\mathrm{Ca}}$ subtypes in IMA. The IMA sections were incubated with the indicated antibodies before stained with 3,3'-diaminobenzidine and counterstained with Mayer's haematoxylin (C). Comparison of the histoscore (H-score) of each $\mathrm{K}_{\mathrm{Ca}}$ subtype in the endothelial cell (EC) and the smooth muscle cell (SMC) layer respectively as well as the overall H-score of each $\mathrm{K}_{\mathrm{Ca}}$ subtype in both cell layers (EC + SMC) (D, n=7) between IMAs with or without homocysteine exposure. ${ }^{*} \mathrm{P}<0.05$, Hcy vs. control. 
demonstrated in the study of vasoconstriction. Previous studies in hyperhomocysteinemic animal models revealed simultaneously increased $\mathrm{TXA}_{2}$ activity both in vessels and platelets (20). We therefore used U46619, a TXA analog, as the vasoconstrictor to study the contractility changes of IMA and the regulatory role of $\mathrm{K}_{\mathrm{Ca}}$ channels under hyperhomocysteinemic condition. Pretreatment of IMA with iberiotoxin significantly enhanced U46619induced constriction. Homocysteine exposure enhanced the response of IMA to U46619 whereas the enhancement effect of iberiotoxin on the vasoconstriction became ignorable, suggesting that homocysteine inhibited the activity of $\mathrm{BK}_{\mathrm{Ca}}$ channels in opposing vasoconstriction in IMA. Previous studies in human coronary arterial myocytes found that $\mathrm{TXA}_{2}$ prostanoid receptor (TP) physically associates with $\mathrm{BK}_{\mathrm{Ca}} \alpha$-subunit, resulting in channel inhibition after agonist stimulation. Such TPinduced trans-inhibition of $\mathrm{BK}_{\mathrm{Ca}}$ channel activity promotes vasoconstriction induced by U46619 (21). Further study demonstrated that the $\beta 1$-subunit of $\mathrm{BK}_{\mathrm{Ca}}$ can by itself interact with TP meanwhile can assemble in a tripartite complex with $\mathrm{BK}_{\mathrm{Ca}} \alpha$ and TP. $\beta 1$ is able to reduce TP agonist $\mathrm{TXA}_{2}$-induced $\mathrm{BK}_{\mathrm{Ca}} \alpha$ inhibition and thus vasoconstriction. It was observed that U46619-induced contractile response of aortic rings was increased in $\beta 1^{-/}$mice compared with those from $\beta 1^{+/+}$animals (22). In our study, we found that homocysteine decreased the expression of $\mathrm{BK}_{\mathrm{Ca}} \beta 1$-subunit in IMA, which may explain the enhancement of U46619induced IMA constriction after homocysteine exposure. Previously we demonstrated that homocysteine induces ER stress in porcine coronary arteries and PERK-dependent activation of forkhead box $\mathrm{O} 3 \mathrm{a}$ (FoxO3a) mediates $\mathrm{BK}_{\mathrm{Ca}}$ $\beta 1$ degradation via upregulating the E3 ubiquitin ligase atrogin-1. This mechanism might also be involved in homocysteine-induced loss of $\mathrm{BK}_{\mathrm{Ca}} \beta 1$ in IMA, though further studies are warranted to validate this.

In comparison with the $\mathrm{BK}_{\mathrm{Ca}}$ subtype that is of importance in mediating relaxation of $\mathrm{IMA}, \mathrm{IK}_{\mathrm{Ca}}$ and $\mathrm{SK}_{\mathrm{Ca}}$ subtypes play a minor role in the tone regulation of IMA under physiological condition despite their expression abundance. Blockade of the $\mathrm{IK}_{\mathrm{Ca}}$ and $\mathrm{SK}_{\mathrm{Ca}}$ subtypes individually or jointly barely suppressed the relaxant response of IMA to acetylcholine, which was consistent with the finding in a previous study from our group (18). Moreover, inhibition of $\mathrm{IK}_{\mathrm{Ca}}$ and $\mathrm{SK}_{\mathrm{Ca}}$ subtypes had no impact on U46619-induced vasoconstriction. However, after homocysteine exposure, $\mathrm{IK}_{\mathrm{Ca}}$ and $\mathrm{SK}_{\mathrm{Ca}}$ subtypes became involved in endothelium-dependent relaxation, evidenced by the significant inhibitory effect of TRAM-34 and apamin on the relaxation. The "unmasking" of the role of $\mathrm{IK}_{\mathrm{Ca}}$ and $\mathrm{SK}_{\mathrm{Ca}}$ channels in mediating endothelium-dependent relaxation may be explained by the inhibition of $\mathrm{NO}$ pathway under hyperhomocysteinemic condition. The loss of NO-mediated relaxation may augment the vasodilating activity of EDHF whose action is mediated by endothelial $\mathrm{IK}_{\mathrm{Ca}}$ and $\mathrm{SK}_{\mathrm{Ca}}$ channels (23). The augmentation of $\mathrm{IK}_{\mathrm{Ca}}$ and $\mathrm{SK}_{\mathrm{Ca}}$ channel involvement may be a mechanism to compensate for homocysteine-induced loss of $\mathrm{BK}_{\mathrm{Ca}}$ channel function. It is unclear how homocysteine augmented the role of $\mathrm{IK}_{\mathrm{Ca}}$ and $\mathrm{SK}_{\mathrm{Ca}}$ channels in IMA relaxation. Both western blot and immunohistochemistry staining experiments showed unaltered protein levels of $\mathrm{IK}_{\mathrm{Ca}}$ and $\mathrm{SK}_{\mathrm{Ca}}$. It might be possible that although homocysteine does not alter the overall expression of these channels, it may affect cell surface density of $\mathrm{IK}_{\mathrm{Ca}}$ and $\mathrm{SK}_{\mathrm{Ca}}$ channels and/or modulate the activity of single channels in the endothelial cells of IMA. Further experiments including cell surface protein analysis and patch clamp recording will be required to test this speculation. In addition, homocysteine did not affect the "no involvement" status of $\mathrm{IK}_{\mathrm{Ca}}$ and $\mathrm{SK}_{\mathrm{Ca}}$ subtypes in the constriction of IMA, indicating that although $\mathrm{IK}_{\mathrm{Ca}}$ and $\mathrm{SK}_{\mathrm{Ca}}$ channels are abundantly expressed in the smooth muscle of IMA, the function of smooth muscle $\mathrm{IK}_{\mathrm{Ca}}$ and $\mathrm{SK}_{\mathrm{Ca}}$ remains elusive, at least they are unessential to smooth muscle tone regulation in IMA. Whether these subtypes are involved in inflammatory responses of endothelial and smooth muscle cells and take part in the process of atherosclerosis in IMA in hyperhomocysteinemia is a topic worthy of investigation.

\section{Study limitations}

The present study investigated the effect of hyperhomocysteinemia on $\mathrm{K}_{\mathrm{Ca}}$ channels in IMA by using an in vitro tissue culture model. The IMA samples were collected from 76 CABG patients who were free from diabetes. Hypertension (68.42\%) and dyslipidemia (32.89\%) are common comorbidities in these patients and current smokers account for $35.53 \%$. Preoperative medications including antihypertensive, lipid-lowering, anti-thrombotic, and coronary dilating drugs were quite common (Table S1). Considering that these cardiovascular risk factors and drug therapies may affect vascular reactivity, we used "paired sample" design in this study to avoid misinterpretation of the results. In each experiment, the IMA sample taken from each patient was divided and treated with or without homocysteine. In this 
way, although we could not rule out the influence posed by the risk factors and pharmacotherapies on the vascular reactivity, we were able to clarify the effect of homocysteine on IMA vasoreactivity and $\mathrm{K}_{\mathrm{Ca}}$ channels. Future studies with stratification shall help further clarify the influence of the risk factors on the effect of homocysteine. Besides, there are several limitations of this study that need to be addressed. First, the concentration of homocysteine was $100 \mu \mathrm{mol} / \mathrm{L}$, which is higher than the plasma homocysteine level in most hyperhomocysteinemic patients $(20-30 \mu \mathrm{mol} / \mathrm{L})$. Although it is not unusual to use high dose of exposure for in vitro studies and $100 \mu \mathrm{mol} / \mathrm{L}$ even millimolar concentrations were often used in in vitro investigation of the effect of homocysteine $(7,18,24,25)$, studies using homocysteine at concentrations more commonly seen in hyperhomocysteinemic patients for prolonged exposure period may be further considered.

Second, it has to be mentioned that the plasma homocysteine concentration of these IMA donors was unknown since CABG patients are not routinely checked for homocysteine level in our hospital. Considering the incidence of hyperhomocysteinemia in patients with coronary artery disease, it is possible that some of the IMAs had already been subjected to high concentration of homocysteine in vivo before the in vitro exposure. However, in this study, the IMA used in every single experiment was divided from a same patient. In comparison to random assignment of IMAs from different individuals to control and treatment groups, this design helped rule out the influence of clinical characteristics of different patients on the $\mathrm{K}_{\mathrm{Ca}}$ channels and at the same time minimized the impact of plasma homocysteine status on the data interpretation. Nevertheless, further strengthening the study with comparison of $\mathrm{K}_{\mathrm{Ca}}$ channels in IMAs between hyperhomocysteinemic and non-hyperhomocysteinemic patients will be the direction for future studies.

Another limitation is that although we demonstrated that homocysteine inhibits the $\mathrm{BK}_{\mathrm{Ca}}$ channel activity and augments the activity of $\mathrm{IK}_{\mathrm{Ca}}$ and $\mathrm{SK}_{\mathrm{Ca}}$ channels in IMA dilatation, direct electrophysiological measurements of the channel activities were not performed despite our experience in the patch-clamp recording of $\mathrm{K}_{\mathrm{Ca}}$ channels in vascular cells $(7,15,16,26)$. Due to the limited amount of residual IMA graft obtained from each patient, we were unable to enzymatically disassociate enough endothelial and smooth muscle cells for satisfactory primary culture for the subsequent patch-clamp recording. Optimization of tissue preparation procedures and cell disassociation and culture conditions etc. needs to be implemented to help realize electrophysiological measurements in future studies.

\section{Conclusions}

Homocysteine compromises the vasodilating activity of $\mathrm{BK}_{\mathrm{Ca}}$ channels in IMA, which is associated with a loss of the $\mathrm{BK}_{\mathrm{Ca}} \beta 1$-subunit. Unlike $\mathrm{BK}_{\mathrm{Ca}}, \mathrm{IK}_{\mathrm{Ca}}$ and $\mathrm{SK}_{\mathrm{Ca}}$ channels are unessential for the regulation of vasoreactivity in IMA, while the loss of $\mathrm{BK}_{\mathrm{Ca}}$ channel functionality in hyperhomocysteinemia enhances the role of $\mathrm{IK}_{\mathrm{Ca}}$ and $\mathrm{SK}_{\mathrm{Ca}}$ channels in mediating endothelial dilator function. These findings provided new mechanistic insights into the dysregulation of vascular tone in patients with hyperhomocysteinemia. Moreover, we suggest that targeting $\mathrm{BK}_{\mathrm{Ca}}$ channels may form a strategy to improve the postoperative graft performance in CABG patients with hyperhomocysteinemia who receive IMA grafting.

\section{Acknowledgments}

We thank Ms. Jing Zhang from Yuebin Medical Research Laboratory for technical support in immunohistochemistry experiments.

Funding: This study was supported by National Natural Science Foundation of China 81870227, Tianjin Municipal Science and Technology Commission 18PTZWHZ00060 \& 20JCZDJC00510, Key Medical Program of Tianjin Binhai New Area Health Bureau 2018BWKZ005, Research Fund of TEDA International Cardiovascular Hospital 2018-TD001, and the Non-profit Central Research Institute Fund of Chinese Academy of Medical Sciences 2019XK310001.

\section{Footnote}

Reporting Checklist: The authors have completed the MDAR reporting checklist. Available at http://dx.doi.org/10.21037/ atm-20-6821

Data Sharing Statement: Available at http://dx.doi. org/10.21037/atm-20-6821

Conflicts of Interest: All authors have completed the ICMJE uniform disclosure form (available at http://dx.doi. org/10.21037/atm-20-6821). The authors have no conflicts of interest to declare.

Ethical Statement: The authors are accountable for all aspects of the work in ensuring that questions related 
to the accuracy or integrity of any part of the work are appropriately investigated and resolved. The study was conducted in accordance with the Declaration of Helsinki (as revised in 2013). The study was approved by the Institutional Ethics Review Board of TEDA International Cardiovascular Hospital ([2018]-0626-2). Written informed consent was obtained from all patients.

Open Access Statement: This is an Open Access article distributed in accordance with the Creative Commons Attribution-NonCommercial-NoDerivs 4.0 International License (CC BY-NC-ND 4.0), which permits the noncommercial replication and distribution of the article with the strict proviso that no changes or edits are made and the original work is properly cited (including links to both the formal publication through the relevant DOI and the license). See: https://creativecommons.org/licenses/by-nc-nd/4.0/.

\section{References}

1. Ganguly P, Alam SF. Role of homocysteine in the development of cardiovascular disease. Nutr J 2015;14:6.

2. Chen C, Conklin BS, Ren Z, et al. Homocysteine decreases endothelium-dependent vasorelaxation in porcine arteries. J Surg Res 2002;102:22-30.

3. Jiang X, Yang F, Tan H, et al. Hyperhomocystinemia impairs endothelial function and eNOS activity via PKC activation. Arterioscler Thromb Vasc Biol 2005;25:2515-21.

4. Topal G, Brunet A, Millanvoye E, et al. Homocysteine induces oxidative stress by uncoupling of $\mathrm{NO}$ synthase activity through reduction of tetrahydrobiopterin. Free Radic Biol Med 2004;36:1532-41.

5. Cheng Z, Jiang X, Kruger WD, et al. Hyperhomocysteinemia impairs endothelium-derived hyperpolarizing factor-mediated vasorelaxation in transgenic cystathionine beta synthase-deficient mice. Blood 2011;118:1998-2006.

6. De Vriese AS, Blom HJ, Heil SG, et al. Endotheliumderived hyperpolarizing factor-mediated renal vasodilatory response is impaired during acute and chronic hyperhomocysteinemia. Circulation 2004;109:2331-6.

7. Wang XC, Sun WT, Yu CM, et al. ER stress mediates homocysteine-induced endothelial dysfunction: Modulation of IKCa and SKCa channels. Atherosclerosis 2015;242:191-8.

8. Ledoux J, Werner ME, Brayden JE, et al. Calciumactivated potassium channels and the regulation of vascular tone. Physiology (Bethesda) 2006;21:69-78.

9. Ghatta S, Nimmagadda D, Xu X, et al. Large-conductance, calcium-activated potassium channels: structural and functional implications. Pharmacol Ther 2006;110:103-16.

10. Eichhorn B, Dobrev D. Vascular large conductance calcium-activated potassium channels: functional role and therapeutic potential. Naunyn Schmiedebergs Arch Pharmacol 2007;376:145-55.

11. Bolotina VM, Najibi S, Palacino JJ, et al. Nitric oxide directly activates calcium-dependent potassium channels in vascular smooth muscle. Nature 1994;368:850-3.

12. Archer SL, Gragasin FS, Wu X, et al. Endotheliumderived hyperpolarizing factor in human internal mammary artery is 11,12-epoxyeicosatrienoic acid and causes relaxation by activating smooth muscle $\mathrm{BK}(\mathrm{Ca})$ channels. Circulation 2003;107:769-76.

13. Cai B, Gong D, Pan Z, et al. Large-conductance $\mathrm{Ca} 2+-$ activated $\mathrm{K}+$ currents blocked and impaired by homocysteine in human and rat mesenteric artery smooth muscle cells. Life Sci 2007;80:2060-6.

14. Au ALS, Seto SW, Chan SW, et al. Modulation by homocysteine of the iberiotoxin-sensitive, $\mathrm{Ca} 2+-$ activated $\mathrm{K}+$ channels of porcine coronary artery smooth muscle cells. Eur J Pharmacol 2006;546:109-19.

15. Sun WT, Wang XC, Mak SK, et al. Activation of PERK branch of ER stress mediates homocysteine-induced BKCa channel dysfunction in coronary artery via FoxO3a-dependent regulation of atrogin-1. Oncotarget 2017;8:51462-77.

16. Sun WT, Wang XC, Novakovic A, et al. Protection of dilator function of coronary arteries from homocysteine by tetramethylpyrazine: Role of ER stress in modulation of BKCa channels. Vascul Pharmacol 2019;113:27-37.

17. Hou HT, Wang J, Zhang X, et al. Endothelial nitric oxide synthase enhancer AVE3085 reverses endothelial dysfunction induced by homocysteine in human internal mammary arteries. Nitric Oxide 2018;81:21-7.

18. Sun WT, Hou HT, Chen HX, et al. Calcium-activated potassium channel family in coronary artery bypass grafts. J Thorac Cardiovasc Surg 2019;S0022-5223(19)33456-7.

19. Mistry DK, Garland CJ. Nitric oxide (NO)-induced activation of large conductance $\mathrm{Ca} 2+-$ dependent $\mathrm{K}+$ channels $(\mathrm{BK}(\mathrm{Ca}))$ in smooth muscle cells isolated from the rat mesenteric artery. Br J Pharmacol 1998;124:1131-40.

20. Koller A, Szenasi A, Dornyei G, et al. Coronary microvascular and cardiac dysfunction due to homocysteine pathometabolism; a complex therapeutic design. Curr 
Pharm Des 2018;24:2911-20.

21. Li M, Tanaka Y, Alioua A, et al. Thromboxane A2 receptor and MaxiK-channel intimate interaction supports channel trans-inhibition independent of G-protein activation. Proc Natl Acad Sci USA 2010;107:19096-101.

22. Li M, Zhang Z, Koh H, et al. The beta1-subunit of the MaxiK channel associates with the thromboxane A2 receptor and reduces thromboxane A2 functional effects. J Biol Chem 2013;288:3668-77.

23. Edwards G, Feletou M, Weston AH. Endotheliumderived hyperpolarising factors and associated pathways: a

Cite this article as: Sun WT, Xue HM, Hou HT, Chen HX, Wang J, He GW, Yang Q. Homocysteine alters vasoreactivity of human internal mammary artery by affecting the KCa channel family. Ann Transl Med 2021;9(8):625. doi: 10.21037/atm-206821 synopsis. Pflugers Arch 2010;459:863-79.

24. Wu X, Zhang L, Miao Y, et al. Homocysteine causes vascular endothelial dysfunction by disrupting endoplasmic reticulum redox homeostasis. Redox Biol 2019;20:46-59.

25. Jin L, Caldwell RB, Li-Masters T, et al. Homocysteine induces endothelial dysfunction via inhibition of arginine transport. J Physiol Pharmacol 2007;58:191-206.

26. Han JG, Yang Q, Yao XQ, et al. Role of large-conductance calcium-activated potassium channels of coronary arteries in heart preservation. J Heart Lung Transplant 2009;28:1094-101. 
Supplementary

Table S1 Characteristics of the 76 CABG patients and preoperative medications

\begin{tabular}{|c|c|}
\hline Characteristics & Number of patients (\% of the total patients) \\
\hline Male & $64(84.21 \%)$ \\
\hline Female & $12(15.79 \%)$ \\
\hline \multicolumn{2}{|l|}{ Age (year) } \\
\hline$>65$ & $31(40.79 \%)$ \\
\hline \multicolumn{2}{|l|}{ BMI } \\
\hline$<18.5$ & $1(1.32 \%)$ \\
\hline$>18.5<24$ & $21(27.63 \%)$ \\
\hline Stage I & $2(2.63 \%)$ \\
\hline Stage II & $17(22.37 \%)$ \\
\hline Stage III & $33(43.42 \%)$ \\
\hline Dyslipidemia $(\mathrm{TC} \geq 6.2 \mathrm{mmol} / \mathrm{L}$ or $\mathrm{LDL} \geq 4.1 \mathrm{mmol} / \mathrm{L}$ or $\mathrm{TG} \geq 2.3 \mathrm{mmol} / \mathrm{L}$ ) & $25(32.89 \%)$ \\
\hline Current smoker & $27(35.53 \%)$ \\
\hline Anti-hypertensive drugs ${ }^{\#}$ & $73(96.05 \%)$ \\
\hline 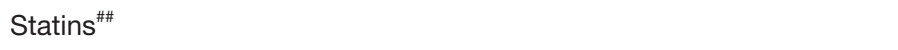 & $69(90.79 \%)$ \\
\hline Coronary dilating drugs & $68(89.47 \%)$ \\
\hline
\end{tabular}

"Non-hypertensive patients who received beta-blockers at least 24 hours before CABG to reduce the incidence or complications of postoperative atrial fibrillation were also counted. \#\#Patients without dyslipidemia who received statins at least 24 hours before CABG to reduce risks of postoperative major adverse cardiovascular and cerebral events were also counted. CABG, coronary artery bypass surgery; BMI, body mass index; TC, total cholesterol; TG, triglyceride; LDL, low-density lipoprotein cholesterol. 